\title{
Erratum
}

Diabetes Metab J 2021;45:797

https://doi.org/10.4093/dmj.2021.0251

pISSN 2233-6079 • eISSN 2233-6087

\section{MondoA Is Required for Normal Myogenesis and Regulation of the Skeletal Muscle Glycogen Content in Mice}

Hui Ran ${ }^{1}$, Yao Lu ${ }^{1}$, Qi Zhang ${ }^{1}$, Qiuyue Hu${ }^{1}$, Junmei Zhao ${ }^{2}$, Kai Wang ${ }^{3}$, Xuemei Tong ${ }^{4}$, Qing Su${ }^{1}$

${ }^{1}$ Department of Endocrinology, Xinhua Hospital, Shanghai Jiao Tong University School of Medicine, Shanghai,

${ }^{2}$ Department of Hematology, Renmin Hospital, Wuhan University, Wuhan,

${ }^{3}$ Department of Pediatrics, 1st Affiliated Hospital, Zhengzhou University, Zhengzhou,

${ }^{4}$ Department of Biochemistry and Molecular Cell Biology, Shanghai Key Laboratory for Tumor Microenvironment and Inflammation,

Key Laboratory of Cell Differentiation and Apoptosis of Chinese Ministry of Education, Shanghai Jiao Tong University School of Medicine,

Shanghai, China

Diabetes Metab J 2021;45:439-451. https://doi.org/10.4093/dmj.2019.0212

There was an error in the Fig. 4F. A corrected version of Fig. 4F is attached.

We apologize for any inconvenience that this may have caused.
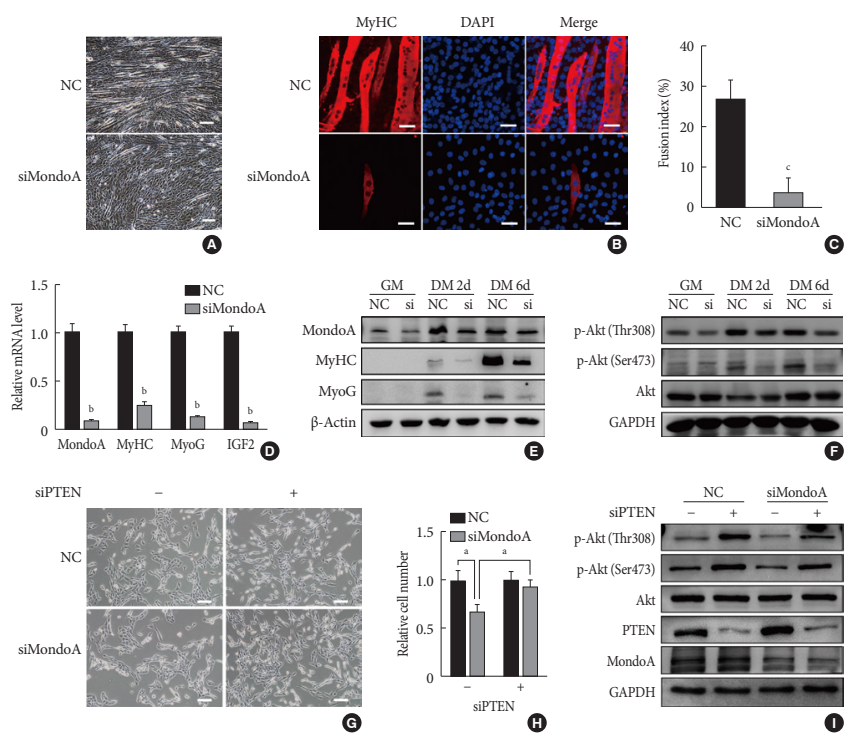

This is an Open Access article distributed under the terms of the Creative Commons Attribution Non-Commercial License (https://creativecommons.org/licenses/by-nc/4.0/) which permits unrestricted non-commercial use, distribution, and reproduction in any medium, provided the original work is properly cited. 